\title{
CONFERENCIA
}

\section{HABILIDADES PARA EL RAZONAMIENTO Y TRANSFERENCIA DE CONOCIMIENTOS CON EL ENTORNO MEDIANTE EL USO CREATIVO DE VIDEOCLIPS EN LAS CIENCIAS ANATÓMICAS.}

\author{
Cristian STEFAN* y Andreas WEIGLEIN** \\ *Touro University College of Medicine, Hackensack, New Jersey, USA and "Medical University Graz, Graz, \\ Austria
}

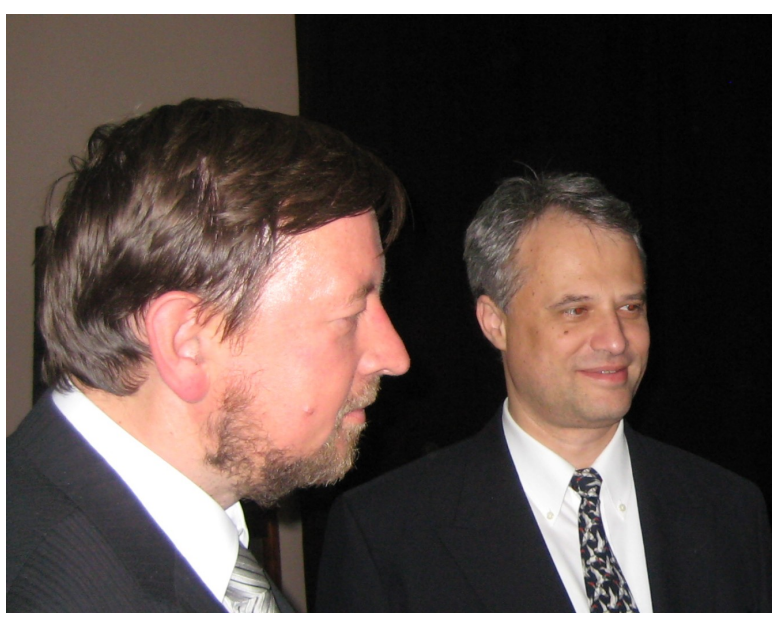

La necesidad de cambio de la enseñanza de las ciencias anatómicas de descriptiva a funcional y con orientación clínica durante todo el curriculum, representa una oportunidad especial y un desafío para encontrar modalidades activas suplementarias de aprendizaje que incrementen el interés de los estudiantes por el tema, mejoren la retención del conocimiento y ofrezcan una oportunidad adicional para los ejercicios de resolución de problemas y auto-evaluación. El uso de video-clips de películas médicas y no médicas están dirigidas a estimular la habilidad de los estudiantes para la observación e interpretación de hechos y la aplicación del conocimiento teórico acumulado a diversos contextos y situaciones. La conferencia presentará una propuesta educativa creativa en esta dirección y proporcionará ejemplos. Se usarán varios videoclips como base para la discusión de aspectos relacionados a procesos anatómicos, fisiológicos y fisiopatológicos, y vincularlos con principios históricos y del examen físico asociados a ellos. El método enfatiza las habilidades observacionales y de razonamiento en un entorno de aprendizaje amigable. Además, el método agrega un componente emocional que acrecienta la experiencia educativa. 